fault with the endowment of the other schools; medical education has grown with the vast progress of science to be such a difficult and financially unprofitable business that it may make a very reasonable claim to be assisted by the State when necessary. What we protest against is the unfairness and injustice of endowing one or more schools while absolutely ignoring the claims of another, which has done at least as good work, and against which no fault has been found. These rival schools will now be free from all possibility of pecuniary embarrassment, they will be provided with abundant funds for the equipment of laboratories and class-rooms, the salaries of their professors and lecturers will be paid for them, no inconsiderable number of rich prizes will be offered to them as bribes to entice students, and, worst of all, they can outbid and undersell the School of the Royal College of Surgeons by lowering the fees for lectures, degrees, and diplomas to such a point as must speedily starve and destroy our School. It is a matter of common knowledge that these things are actually being done, and this with funds supplied by the State, which should protect the interests of all alike, and to which all taxpayers are compelled to contribute. The scandalous injustice and unfairness of the scheme are so manifest that there is no need of an elaborate argument on the subject. When the Bill for the formation and endowment of the new Universities, which were to take over and absorb the four existing medical schools in Ireland outside Trinity College, was being introduced, the President and Council of the Royal College of Surgeons had full confidence that we should only have to state our case in order to have our grievance remedied. We therefore approached the Government and asked for such an endowment as would enable us to continue our work in the face of the new and increased competition. The sum we applied for was absolutely insignificant compared with the huge grants which were being voted for educational purposes for the new universities. In appruaching the Government we felt all the more confident of success as the institution which we represent is an educational institution with a continuous record for a hundred years of good work done, absolutely non-sectarian and non-political, a common meeting ground for men of every religion and every shade of political thought, with equal privileges for all. The Royal College of Surgeons did not spare trouble, work, or expense in making its position clear to the Government. We sent several deputations to London, who spent many hours in the Lobbies of the House of Commons interviewing Members of Parliament, including the heads of both political parties and the Chief Secretary for Ireland, and finally an audience of the Prime Minister was obtained. Mr. Asquith paid in words a high and glowing tribute to the good work which had been done by the College and the School, but in deed he paid a very poor tribute to our intelligence, for he then proceeded to assure us that he did not think that either the School or the College would suffer by the new competition, but that if it were proved later on that they were really damaged, as was feared, then the Government might possibly reconsider the question, though he would not promise it. The result was therefore a complete failure. After all our trouble, loss of time, and expense we received in return only a number of high-flown complimentary phrases eulogising the good work which we had done.

[Mr. Lentaigne here discussed the question whether the failure of the negotiations with the Government was not due to the non-political attitude of the College and to the absence of support from any religious or political party with votes in Parliament. He illustrated the preferential State endowment of certain medical schools by a sketch of the results which might be expected from preferential endowment of one among several commercial firms, and continued as follows:]

The Royal College of Surgeons is nevertheless determined to spare no effort to maintain the highest possible standard of efficiency in its School. During the past two months it has expended large sums out of its scanty funded capital in improving the School, and it will do everything in its power to maintain the unequal struggle as long as it would be possible; it will also agitate to the best of its ability, spreading far and wide, and on every possible occasion, the story of the wrong which was being done. My term of office as President will end in May next, but another will succeed me, and after him another again, and they and the Conncil will all continue the agitation until they get redress. Owing to the peculiar conditions of professional life in Ireland the interests of the Royal College of Surgeons were bound up in the School. Every one of its 400 Fellows and every one of its 3000 Licentiates when receiving his diploma takes an oath always to uphold the honour and dignity of the College to the utmost of his ability, and each of them will abide by that oath.

\section{TWO CASES OF INTESTINAL OBSTRUCTION IN WHICH A DOUBLE RESECTION \\ OF INTESTINE WAS PERFORMED.}

BY HUGH M. RIGBY, M.S. Lond., F.R.C.S. ENG.,

SURGEON-LN-ORDINARY TO H.R.H. THE PRINCE OF WALES; ASSISTAN' SURGEON TO THE LONDON HOSPITAL; SURGEON TO THE POPLAR HOSPITAT.

THE two cases of acute intestinal obstruction which are here described presented so many interesting problems during their treatment that I considered their publication worthy of record. In both complications occurred which demanded numerous operations, and in both a double resection of intestine was ultimately required. The condition of carcinomatous stricture of the large intestine complicated by acute obstruction generally necessitates three operations before the condition is satisfactorily relieved. These include (1) exploration of the abdomen followed by drainage of the distended gut above the stricture ; (2) resection of the growth when this is possible; and (3) an operation to close the artificial opening at a later date. In certain cases, where distension of the gut is slight and fæcal stasis has not occurred to any great extent, an artificial opening can be avoided by the formation of a lateral anastomosis. Unfortunately this is not often possible, especially in hospital practice. When it is possible, however, it affords a great saving of discomfort and danger to the patient.

When the stricture (as in Case 1) is situated at the splenic flexure of the colon, the opening for drainage may be made in any portion of the colon above or in the lower part of the small intestine. In Case 1 for purposes of drainage an extraperitoneal opening into the ascending colon was made in the right loin. This proved difficult to close satisfactorily at the third operation. When the obstruction recurred, however, it was re-opened easily and without danger of peritoneal infection. It is interesting to notice that this opening appears now to have closed completely, although it leads into a large cul-de-sac formed of small and great intestine. In such conditions a small mucous fistula generally persists, and probably the present closure is only a temporary one. In Case 2 the treatment of the large fistulous opening into the cæcum was the most difficult part of the problem, and the treatment adopted, although successful, was somewhat drastic. It is of interest to note that this patient is now in sound health and well up to his normal weight, although deprived of most of his large and several feet of small intestine.

CASE 1. - The patient was a female, aged 31 years, whom I first saw in February, 1908, in consultation with Dr. Gordon Wilson. She gave the following history. Five days previously she had been seized with abdominal pain of a colicky nature ; the pain was chiefly in the centre of the abdomen, but radiated towards the region of the cæcum. The pain made her feel sick and she had romited several times. The bowels were confined and had only acted slightly after enemata had been given. The temperature was not raised above the normal. On examining the patient she did not appear to be very ill; her pulse was full and regular; the tongue was furred; she did not appear to be in much pain. The abdomen was somewhat distended all over, but this was most marked over the cæcum, and deep palpation caused pain in this region. The abdominal wall was not rigid. A tumour could not be felt in the abdomen. A rectal examination revealed a sense of fulness in Douglas's pouch, but no increased tenderness was caused by the examination. Her previous health had been good, and she gave no history suggestive of old intestinal trouble. An exploratory operation was advised and this was carried out next morning.

First operation.- The abdomen was opened by an incision in the middle line below the umbilicus. The intestines were 
then seen to be distended, but most markedly in the region surrounding tissues. The edges of the intestinal opening of the cæcum. The sigmoid colon was found to be small were freshened and sutured together with catgut sutures. and contracted. The ascending colon was distended; on The margins were then inverted and a second row of chromic tracing the transverse colon across the abdomen a hard ring- catgut sutures was applied. The muscles of the loin were like constriction was met in the splenic flexure. Owing to next sutured over the intestine with chromic catgut and the the general intestinal distension it was obvious that drain- skin edges were united partially, a drainage-tube being left age was necessary. After a little consideration as to where at the lower extremity. This operation dic not prove immethe opening should be made it was decided to drain the diately satisfactory. The portion of the wound where the ascending colon in the right loin. This was done without opening the peritoneum and a large quantity of fæcal matter was evacuated. The median abdominal wound had previously been sutured. A Paul's tube was fixed in the ascending colon and the patient was put back to bed. She made a good recovery from this operation; the loin tube drained well and the median wound healed soundly. Three weeks later I decided to excise the growth at the splenic flexure. For this purpose the patient was admitted into one of my beds in the London Hospital on March 19th, 1908.

Second operation.-The following operation was performed on March 27th, 1908. An incision was made through the left rectus muscle near its outer border about $3 \frac{1}{2}$ inches in length. The affected portion of the intestine with the growth was drawn out on the surface of the abdominal wall. The surrounding parts were protected with gauze. The growth with about 2 inches of intestinal wall on each side was removed, the mesentery having been previously ligatured

FIG. 1.

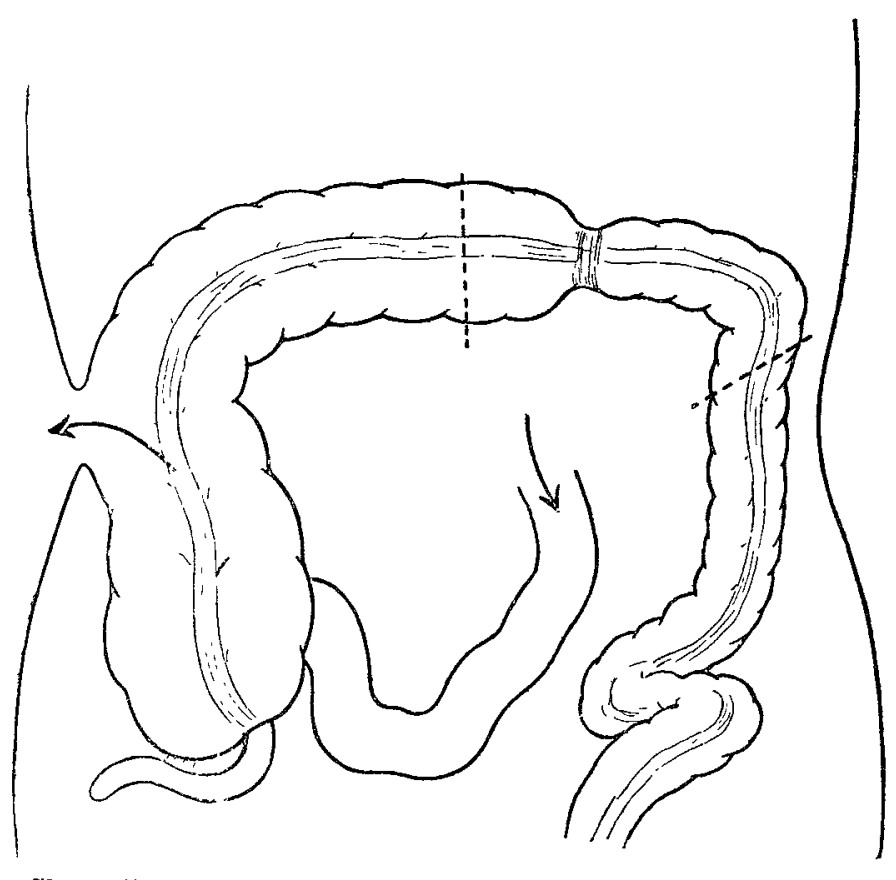

Shows the condition of the intestine before the fifth operation. tube was inserted never healed completely, and a week after the operation slight fæcal discharge occurrel.

The patient was discharged from the hospital on May 21st in good health, but with a small sinus in the right loin. She came to see me at the London Hospital in the following October. She appeared then to be in very good health; she had gained over 1 stone in weight. The colotomy sinus had completely closed. The bowels acted normally and her appetite was good. She occasionally had aching pains at the site of the colotomy scar. The abdomen appeared normal.

On May 25th, 1909, the patient again came to see me at the London Hospital, when she gave the following history. One month previously she began to have attacks of colicky abdominal pain in the lower abdomen and on both sides. This was relieved at first by taking aperients. Six dars before admission she began to vomit and had vomited each day two or three times a day. The bowels had lately acted and divided. Some enlarged glands were also found in the mesentery; these were dissected out freely. The divided ends of the intestine were then united by end-to-end anastomosis ; a double row of chromic gut sutures were used for the union, and some additional fine silk sutures were superimposed at various points. The abdominal wound was then closed without drainage.

The patient stood the operation very well and had but little shock. The specimen removed showed a carcinomi of the scirrhous type encircling the bowel and causing almost complete constriction of its lumen. The glands were examined microscopically, but no secondary deposits were found. The patient made a good recovery from this operation. On April 6th I made the following note: "There is now only slight discharge from the lumbar colotomy opening. Formed motions are passed by the rectum. The sutures were removed to-day; some slight suppuration had occurred in the deeper part of the wound. The patient is comfortable and takes food well." Further progress was good and the abdominal wound healed soundly. The colotomy wound had appreciably contracted, but there was still daily discharge of fæces in small quantity. On May 1st, 1908, the following attempt was made to close this opening.

Third cperation. - The patient was placed on the left side. An incision was then made on each side of the colotomy opening. The margins of the wound were dissected away and the opening into the intestine was freed from the
FIG. 2.
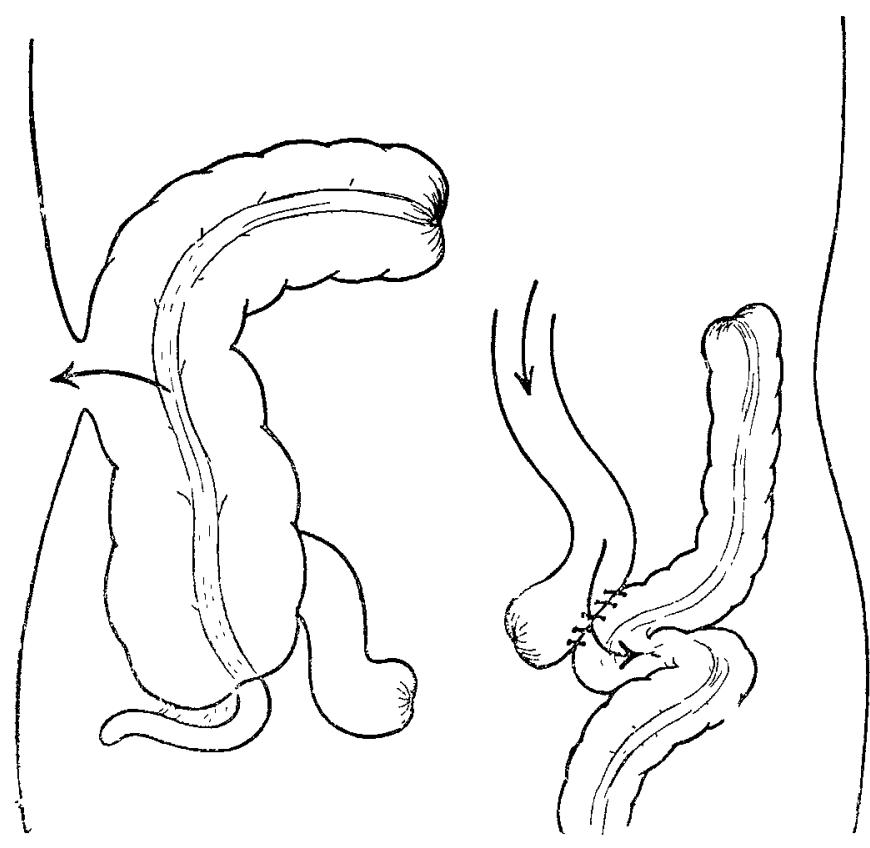

Shows the condition after the fifth operation.

irregularly, and only very small liquid evacuations were passed containing some blood and a little slime. She had lost weight since November. The physical signs were as follows. The abdomen was somewhat distended; no peristaltic waves were seen. The colotomy scar looked red and was tender; there was distinct bulging in the right loin The temperature was $100^{\circ}$; the pulse was 108 , regular. The symptoms were evidently those of intestinal obstruction, probably due to recontraction at the site of the anastomosis.

Fourth operation.-On May 26th, 1909, my colleague Mr. Russell J. Howard, in my absence, opened the old colotomy wound and evacuated a large quantity of fluid fæcal material with immediate relief to the symptoms. The colotomy wound discharged freely after this operation and the patient's general condition was greatly improved. There was, however, no passage of fæces by the rectum, and the skin of the right loin became eczematous from the constant irritation. At the patient's request $I$ decided to operate again and attempt both to relieve the obstruction and remedy the fæcal fistula.

Fifth operation.-On June 25th the following operation was performed. The abdomen was opened through the left rectus muscle by an incision below the umbilicus to the left side of the scar made at the first operation. The position of the old anastomosis was explored with the fingers and a bard mass, evidently carcinomatous, was felt at the line of union. 
It was localised and freely moveable and apparently could be excised without much difficulty. The small intestine was next sought for and traced downwards towards the cæcum. Two clamps were then placed on the intestine about four inches apart, the lower one some three inches from the ileocæcal junction. The intestine was tied at two places with chromic gut sutures between the clamps, and the wall was divided transversely between these ligatures. Each end secured by the ligatures was encircled by a purse-string suture of chromic gut, and both were invaginated. The clamps were then removed. A lateral anastomosis by suture was then made between the proximal end of the divided small intestine and the lateral wall of the sigmoid colon. By this means the flow of fæces was diverted from the colotomy opening. Excision of the growth in the colon was next effected. The old anastomosis with the recurrent growth was freely removed as far as possible towards the descending colon on the left and the hepatic flexure on the right side. The mesentery containing some enlarged glands was also freely excised. The divided ends of the colon were treated in a similar way to those of the small intestine. The ends were secured by chromic gut ligatures tied round them, and each in turn was invaginated by chromic gut purse-string sutures encircling the wall an inch or two from the closed end. At the end of this operation the cæcum, lower portion of the small intestine, and the ascending colon were left closed at each end and communicating with the exterior by the right lumbar colotomy opening. (Figs. 1 and 2.)

The patient made a good recovery from this operation. The bowels began to act naturally 48 hours afterwards. The discharge from the loin greatly diminished and the condition of the skin rapidly improved. On August 13th the patient returned from a convalescent home in good condition. The colotomy wound has healed and no discharge has been noticed from it for the last seven days. The bowels act regularly without aperients. Her general health and appetite are good. She has gained 2 pounds in weight since the operation. Nov. 1st, 1909: The wound is still healed and the general health is good.

CASE 2.-A male, aged 9 years, was admitted into the London Hospital on Jan. 16th. On the previous day, whilst at school, he was seized with acute abdominal pain accompanied by vomiting. He was sent home and put to bed, and chlorodyne was given. The pain and romiting persisted. Two enemata were given with only a small result. As the acute symptoms did not subside he was sent up to the hospital next day at 8 P.M. His previous health had been good.

Condition on admission. - The boy was well $\mathrm{n}$ ourished, showing marked symptoms of shock apparently due to some acute abdominal lesion. The extremities were cold and the lips were pale. The pulse was small, 140 per minute; the temperature was $99^{\circ} \mathbf{F}$. On examination the abdomen was found to be generally distended; the abdominal wall moved slightly on respiration. On palpation an ill-defined swelling was felt occupying the umbilical and right iliac regions. This was tender, not completely dull to percussion, and did not move during respiration. Over the rest of the abdomen distended coils of intestine could be felt. Nothing abnormal was felt by the rectum. The diagnosis of acute intestinal obstruction seemed clear, and the collapse and general condition of shock suggested the presence of gangrene of the gut. Shortly after admission the following operation was performed.

First operation.-The abdomen was opened by an incision in the right semilunar line immediately over the tumour felt through the abdominal wall. When the peritoneum was opened a large quantity of blood-stained fluid escaped and a coil of gangrenous small intestine appeared. This portion was drawn out of the wound. It was found to be the lower part of the ileum. A coil of gut was found acutely twisted on itself, and across the neck of the twist a fibrous band was seen. This was fixed below in the pelvis, but its attachment upwards was not followed. The band was divided and the coil was untwisted. The portion of gangrenous gut was found to be constricted below about two inches from the ileo-cæcal valve, and above two and a half feet higher up. The gut was black and foul-smelling, the peritoneum had lost its gloss, and ash-grey patches were seen on its surface. A stout chromic gut ligature was carried round the healthy gut above the upper and below the lower constriction; intestinal clamps were then applied on the gut between these ligatures, and the gangrenous portion was rapidly cut away. The mesentery was ligatured with chromic gut and was divided piece by piece. A chromic gut purse-string suture was then passed round the intestine about 2 inches away from the ligatured ends. The latter were then inverted and secured by this suture. A lateral anastomosis by suture was then made between the lateral wall of the cæcum and the side of the ileum, some 3 inches from its proximal occluded extremity. The peritoneal cavity in the neighbourhood was cleansed with sponges and the abdomen was closed, a drainage-tube being left in the lower end of the wound. During the operation the patient was much collapsed and two injections of strychnine were given. Brandy and saline injections were given by the rectum on his return to the ward. The gangrenous portion removed was measured and found to be $2 \frac{1}{2}$ feet in length. Fig. 3 shows the condition of the intestine after the first operation.

The patient rallied well from the effects of this operation. On the next day the pulse was 136 per minute ; the temperature was normal. He had slight post-anæsthetic vomiting. Progress was uneventful for the next three days. Abdominal distension caused a good deal of discomfort, but was relieved by enemata containing turpentine. These brought away some fæcal matter and flatus was passed. On the sixth day after operation (Jan. 22nd) the upper end of the wound became acutely inflamed and hot fomentations were applied. On the next day the wound looked worse and had a sloughy greenish appearance. Two sutures were removed and a quantity of greenish pus with a strong fæcal odour escaped. Subsequently fæces were discharged from the wound and the entire wound gradually gave way.

The condition on Feb. 14th-i.e., one month after the operation-was as follows: "The wound has gaped and fæces are passed several times daily through this opening. Enemata are given by the rectum every other day ; these bring away a certain amount of fæcal material. The fæcal discharge from the wound is sometimes fluid, but often large masses of semisolid fæces are passed. The edges of the wound are beginning to show signs of irritation. The boy's general condition is good and he is not losing ground; he looks no thinner and the pulse is good; he eats well."

The note on March 11th (7 weeks after the operation) said: "There is now a gap $1 \frac{1}{2}$ inches wide and 3 inches long owing to the separation of the wound edges; the floor of this gap is formed by the posterior half of the ileo-cæcal anastomosis. The anterior half of the anastomosis has entirely given way and has become firmly adherent to the edges of the abdominal wound. The posterior wall prolapses occasionally. Some fæcal matter passes into the cæcum, as enemata given by the rectum sometimes remove fæcal contents. The majority of the fæces, however, pass straight out through the fistulous opening. A finger can easily be passed into the ascending colon and down the small intestine. The boy's general condition is good. He looks fatter and his temperature remains normal. The pulse is good. The skin of the abdominal wall round the wound is inflamed and pustular." On March 21st it is noted: "The boy is in much the same condition. Less fæcal matter is passed per rectum and there is a constant fæcal flow, generally fluid, bat sometimes semi-solid, from the wound. He is not thinner and the pulse tension is good. The skin of the abdomen shows intense irritation from the constant fæcal discharge, notwithstanding the greatest care and attention in nursing."

The treatment of this fæcal fistula was now a rather difficult problem. Any direct attempt to close such a large opening seemed inadrisable owing to the septic condition of the wound margins. It was evident that unless the free fæcal discharge could be checked no improvement in the condition of the abdominal wall was to be expected. The only course which recommended itself was that of dividing the small intestine above its junction with the cæcum and joining its proximal end to some portion of the large intestine beyond the fistula. The presence of the fæcal fistula and the septic condition of the skin made this proposed operation one of gravity owing to the great risk of infection of the peritoneum. However, this seemed the best line of treatment and accordingly the second operation was performed on March 28th, 1908.

Second operation.-An incision 4 inches long was made below the umbilicus in the middle line after the site of the fæcal fistula had been carefully cleansed and protected. 
Many adhesions were encountered on opening the peritoneal cavity. The ileum entering the anastomosis was traced back and divided some 4 inches from its junction with the cæcum. Chromic gut ligatures were tied round the gut at two places and the intestine was divided between them. The two ends were then invaginated, the invaginated portion being secured by a purse-string chromic gut suture passed round the intestinal wall. The transverse colon was next sought

FiG. 3.

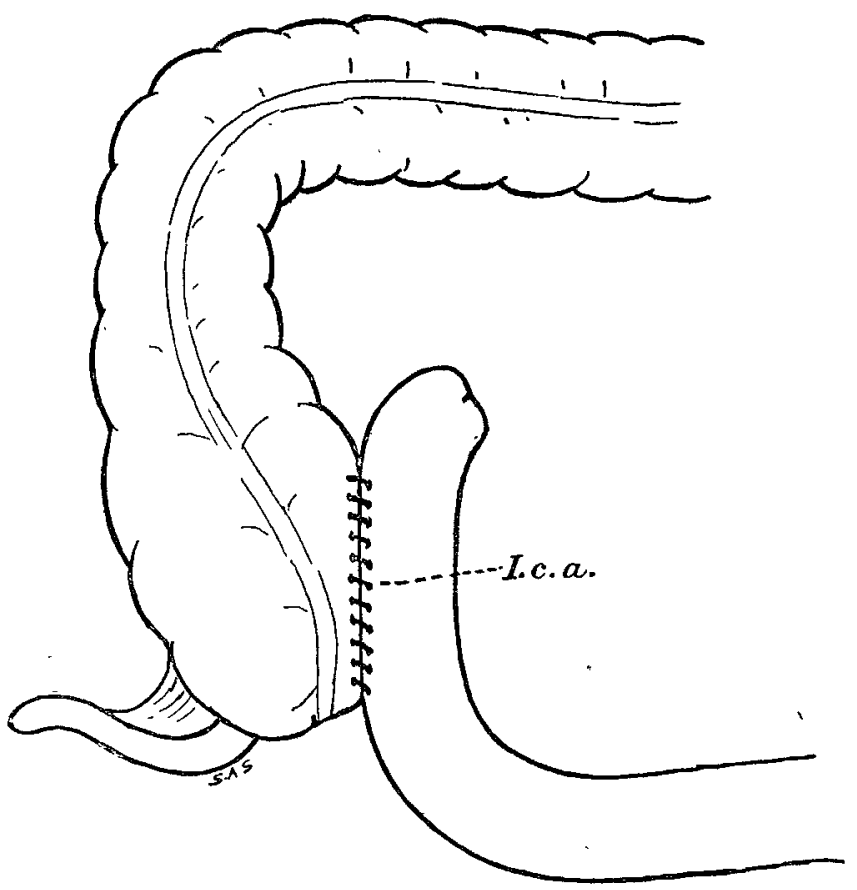

I.c.a., Ileo-cæcal anastomosis.

for and clamps were applied to it and the lower part of the ileum. A lateral anastomosis was then made by suture between these portions of intestine and the abdominal incision was closed: Fig. 4 shows the condition after this operation. The colon was not divided on the proximal side of the anastomosis; this step was considered at the time of operation but was thought inadvisable as an additional risk

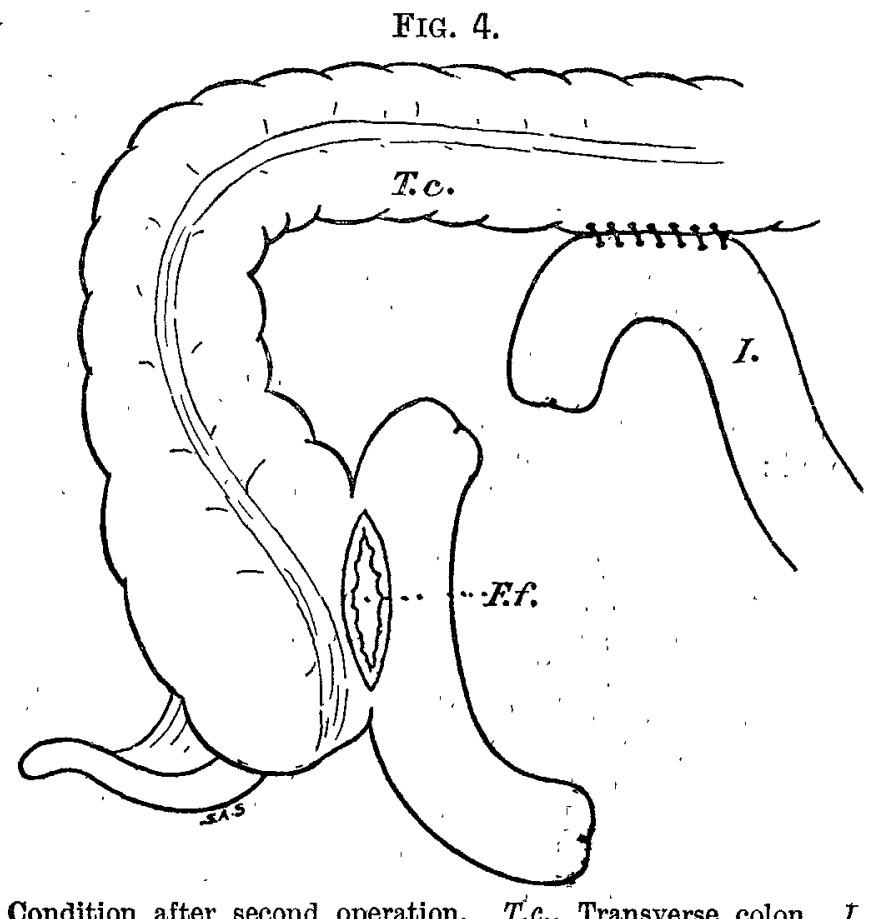

Condition after second operation. T.c., Transverse colon. I.

Ileum. F.f., Fæcal fistula at site of the lateral anastomosis.

owing to the length of the operation and the child's condition.

The boy recovered well from the immediate effects of the operation. There were some abdominal distension and vomiting at first, which passed off after three days, and enemata brought away a good quantity' of fæcal material. The fæcal discharge from the first wound entirely ceased from the date of the second operation. There was some suppuration in the median wound, but this yielded to fomentations with early removal of infected sutures.
The note on April 7th (10 days after the second operation) stated: "The ulceration and pustular condition of the skin round the first wound has entirely healed. There has not been any fæcal discharge at all from this wound since the second operation, but a little mucus comes away every day.". On April 21st (about one month after the second operation) it is noted: "The median incision has healed well. The frcal fistula remains as large as ever; the wound edges, however. are now quite healthy. Up to the present date no fæcal matter had come away, but daily discharge of mucus in small quantity. A few days ago a consiclerable prolapse of mucous membrane took place from the upper part of the wound, apparently from the ascending colon. To-day some fæcal matter was passed from the fistula, coming from the upper part of the wound and evidently from the ileo-colic anastomosis, passing backwards round the hepatic flexure and down the ascending colon."

This condition remained unaltered until May 15th. There was no tendency for the gaping fæcal fistula to close and occasionally fæcal matter was passed from it. The skin,

FIG. 5.

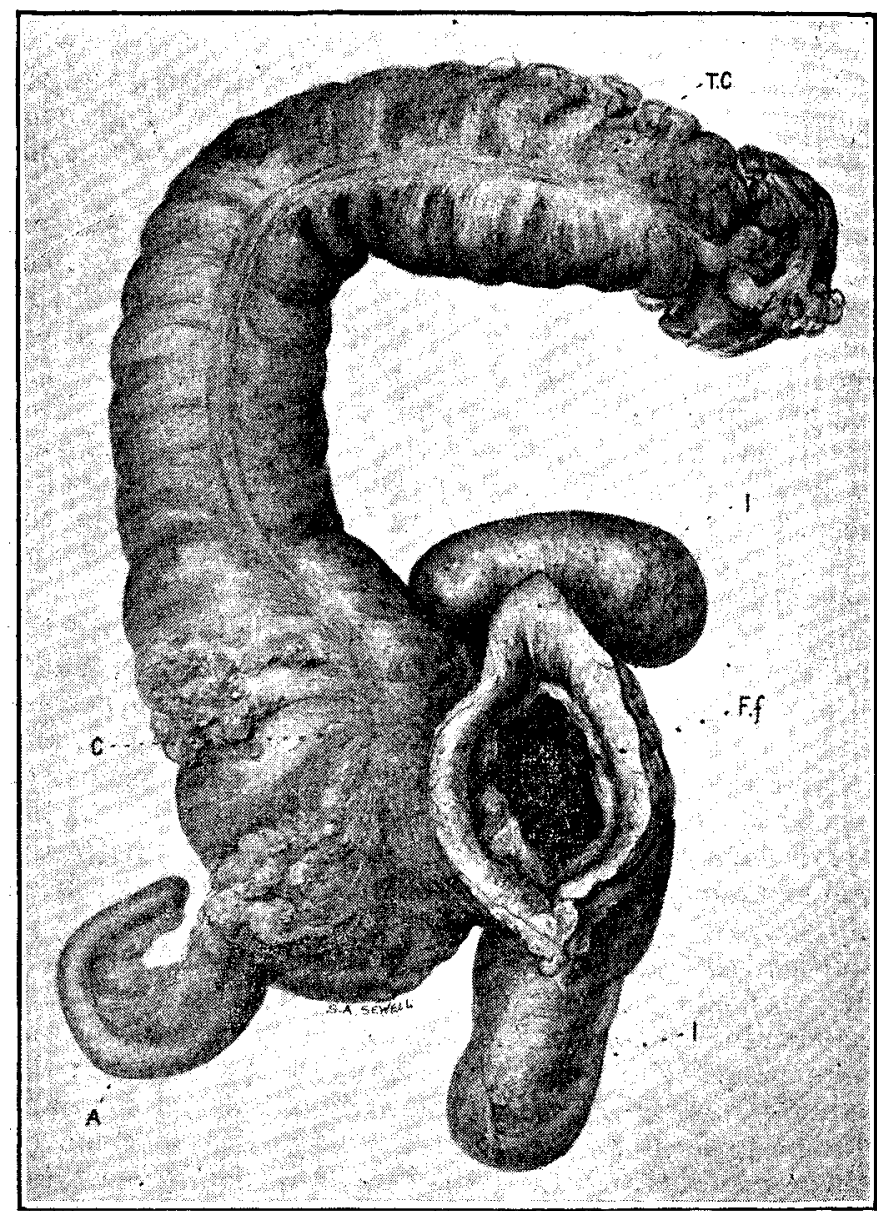

Parts of intestine removed at third operation. A, Appendix cæei. T.C., Transverse colon. I, Ileum. C, Cæcum. Ff., Fæcal fistula.

however, remained in good condition. The boy's general state was very good, the bowels acting well, occasional enemata being necessary. From time to time there was considerable prolapse from the fæcal fistula.

As the general condition of the patient was so good it was considered that an attempt should now be made to close the opening into the cæcum. The following alternative lines of treatment were considered. 1. An operation planned to directly close the opening. The skin was in sound enough condition, but it would have meant free opening of the peritoneal cavity and freshening of the edges of the wound which was still some 3 inches long by $1 \frac{1}{2}$ inches wide. Even if the sutures had held securely and the wound had united an undesirable state of affairs would have resulted. A cul.de-sac of large intestine extending from the middle of the transverse colon to the cæcum and the anastomosed portion of small intestine with two blind ends would have been formed. In this fæcal test-tube fæcal matter and mucus would probably have collected, which might readily cause subsequent trouble, perityphlitis, appendicitis, \&c For these two reasons, therefore, a direct closure of the fæcal 
opening alone was considered inadvisable. 2. The second alternative was that of dividing and closing the colon on the proximal side of the anastomosis made in the transverse colon. This, however, was put aside as it would merely have prevented reflux of fæcal contents. The opening of the fistula was so large that it would probably have never contracted to any great extent, and probably a persistent mucous discharge would continue from the blind tract of bowel left-viz., a portion of the ileum, cæcum, ascending and hepatic flexures of the colon. 3. The third alternative which offered itself as the most certain but at the same time most dangerous one was: Division of the colon between the hepatic flexure and the ileo-colic anastomosis and subsequent removal of the entire portion of bowel left connected with the fistulous opening. After some consideration the last course appeared to be the only satisfactory one, and accordingly the following operation was performed on May 15th, 1908.

Third operation. - Gauze was first packed into the cæcal opening. An incision was then made in healthy skin round and above the mesial side of the opening and the adherent edge of the gut was dissected away from the skin, the peritoneal cavity being frecly opened. The hepatic flexure and transverse colon were brought into the wound and packing was inserted to prevent prolapse of the surround. ing intestines. A chromic gut ligature was passed through the mesocolon and tied round the gut a short distance to the proximal side of the ileo-colic anastomosis A clamp was then placed half an inch nearer the hepatic flexure and the gut was divided between the clamp and the ligature. The ligatured end of the colon was next encircled some 3 inches from its extremity by a purse-string suture of chromic gut and the blind end was invaginated and secured by this suture. Chromic gut ligatures passed by an aneurysm needle were used to tie off successive portions of mesocolon, working gradually downwards from the transverse colon to the cæcum. The wound was next prolonged downwards so as to clear the lower part of the cæcum and attached portion of the ileum. These were then pulled out of the abdomen. The mesentery of this portion of the intestine was ligatured with chromic gut and cut through. An incision was next made around the outer side of the opening in the cæcum and this portion dissected away from the skin and layers of the abdominal wall. The whole portion of intestine, comprising hepatic flexure, ascending colon, cæcum, and attached portion of ileum, was removed en masse. (Fig. 5.) Packs were removed and the abdominal wound was closed by through-and-through silkworm gut sutures and interrupted chromic gut sutures for the muscles. Catgut drains were left in the upper and lower ends of the wound in view of the probability of infection from the contaminated skin. This operation, which lasted 1 hour and 10 minutes, was well borne by the patient.

The after progress was most satisfactory ; some suppuration, as was expected, took place in the wound, but this finally healed up soundly and the patient left hospital on June 25th, 1908. He is now in sound health.

Queen Anne-street, W.

\section{STREPTOCOCCAL INFECTION IN DIPH THERIA : OBSERVATIONS IN EIGHTY CONSECUTIVE CASES.}

By D. MORLEY MATHIESON, M.A., M.D. EdiN., D.P.H., LATE BACTERIOLOGIST AND ASSISTANT MEDICAL OFFICER OF HEAITH, BURGH OF LLITH.

THE frequent occurrence of isolated phenomena about the twelfth or thirteenth day of an attack of diphtheria was first called attention to by Sevestre and Martin. The phenomena which they described consist of one or more of the following: (1) a cutaneous eruption (most frequently scarlatiniform, but in a few cases a simple erythema); (2) joint pains ; (3) albuminuria; and (4) general constitutional disturbance, more or less marked. Sevestre and Martin, and later Roux, suggested that the frequency with which these phenomena developed on or about the thirteenth day seemed to indicate that they were the symptom-complex of a secondary disease, with an incubation period of 13 days, the infection occurring at the time of invasion of the diphtheria. They further suggested that the cause was organismal and probably streptococcic, reasoning from the facts (1) that they frequently found evidence of mixed infection in the bacteriological examination of the throats of these cases; and (2) that they occasionally found similar symptoms develop in pure streptococcic infections of the throat. Antitoxin, they were inclined to believe, had the effect of lowering the resistance of the organism to the attacks of this secondary infection, just as suppuration is more liable to occur in a part poorly supplied with blood.

The following notes refer to observations made in 80 consecutive cases of diphtheria admitted to the Infectious Disease Hospital, Leith. A bacteriological examination of the throat of each case was made on admission and at intervals during the stay in hospital, and the clinical progress was recorded. In 9 of the 80 cases a marked streptococcal infection of the throat was found at one time or other in the course of the disease. Out of these 9,5 developed symptoms corresponding to those described by Sevestre and Martin about the thirteenth day. In the remaining 71 cases where no streptococcal infection of the throat was at any time found, 2 showed epiphenomena about the thirteenth day. In other words: (a) 55 per cent. of the streptococcal cases developed "thirteenth day" symptoms; and (b) 2.8 per cent. of the non-streptococcal cases developed these symptoms.

These results, although they refer to only a limited number of cases, seem to suggest that there is some connexion between the streptococcus infection and the "thirteenth day" phenomena. (As to the part played by antitoxin in lowering the resistance of the tissues to the streptococcic invasion, it. appears to be as probable that the lowered resistance is due to the diphtheria bacillus and its toxins, acting locally and generally.)

The following cases are illustrative :-

CASE 1.-A woman, aged 21 years, was admitted with marked inflammation of both tonsils and a slight filmy patching on their inner surfaces and on the uvula. Swabs taken from the throat showed a few polar-staining KlebsLöffler bacilli and streptococci in long chains. The temperature reached the normal in six days, during which time the throat symptoms gradually cleared up. On the thirteenth day albumin appeared in the urine and a fine punctate rash was seen covering the chest, the upper part of the abdomen, the upper arm, and the back, being very closely aggregated. There was no sickness or headache, and the tongue was not furred. Sore throat was not complained of ; examination revealed streptococci still present, but no diphtheria bacilli. The albuminuria lasted for two days; the rash was of short duration, being practically gone on the evening of the day when it appeared.

CASE 2. - A boy, aged 9 years, came in with a localised patch on the right tonsil. A swab was taken and culture showed Klebs-Löffler bacilli and a few streptococci. The throat cleared up rapidly. On the eighth day an urticarial antitoxin rash developed, lasting 48 hours. On the fourteenth day the patient complained of some pain in the throat and of pain in both shoulders and in the left elbow. In the evening the temperature rose to $100 \cdot 8^{\circ} \mathrm{F}$. Examination of the throat showed a pure culture of streptococci. On the next day the temperature was down, the throat was not painful, and the joint symptoms, though still present in the left shoulder and elbow, were much less severe. On the sixteenth day the patient was quite well. A swab taken from the throat showed that a few streptococci were still present.

CASE 3. - A boy, aged $2 \frac{1}{2}$ years, on admission to hospital was found to have red, swollen tonsils, with some indefinitepatching. Culture showed diphtheria bacilli, streptococci, and staphylococci. The temperature, which was $102 \cdot 4 \circ \mathrm{F}$. on admission, reached the normal on the third morning, and the local symptoms cleared up. Convalescence was uninterrupted, except that on the evening of the twelfth day the child became restless and fretful. When the right ear was examined he cried, and was evidently suffering pain. On the following afternoon a discharge came from this ear and relief was experienced at once. The discharge, which was scanty, continued till the fifteenth day and then stopped. Examination of the discharge showed streptococci and a few rods.

The following is a brief summary of the seven cases in which "thirteenth day" phenomena were observed:-(a) Streptococcal cases: (1) punctate erythema + albuminuria; (2) sore throat + joint pains + rise of temperature $(100.8 \circ \mathrm{F}$.$) ; (3) otorrhœa ; (4) punctate erythema; and (5)$ 